\title{
Measuring Innovative Capacities of the Georgia Regions
}

\author{
Joseph Gogodze
}

\begin{abstract}
European Union (EU) experience reveal that the composite indicators are probably the most useful instruments for measuring the innovative capacities at the regional (sub-national) level. However, some gap exists in the current literature with respect to the elaboration of composite indicators for regional innovation systems (RISs) of developing countries. This article introduces the composite indicators GRIS and GCLS for measuring the regional innovative capacities (for GNUTSI and GNUTS2 territorial classification levels, respectively). Georgia is a useful case-subject because its smallscale developing economy presents special challenges for elaborating the composite indicators for RISs. This article also includes a brief analysis using these composite indicators and indicates the significant heterogeneity among the innovative capacities of the Georgian regions.
\end{abstract}

Keywords: regional innovation systems, composite indicator, factor analysis, clusters, developing countries, countries in transition. 


\section{Introduction}

The regional (sub-national) innovation systems (RIS) play an important role in the innovative potential of a country, and therefore it should be the focus of researchers and policy makers. RIS is a complex multidimensional object, and it is necessary to develop advanced and specialized quantitative instruments to measure and understand the effects of RIS in a particular country.

Presently, the composite indicators are widely used to measure the RIS capacities. As European Union (EU) experience has revealed, the composite indicators are probably the most useful instruments for measuring the innovative capacities at the regional level. Particularly, composite indicators were successfully utilized to appraise the EU Lisbon strategy progress of EU members at the regional level. However, the usefulness of composite indicators hinges on the availability of statistical data. For example, European regional statistical data unavailability for 2002-2003 period did not allow access to the innovative potential of regions other than EUI5's countries. Later, in 2006, substantial revisions of the initial indicators enabled consideration of EU new member's regions (Hollanders, 2007).

The analysis of RIS has been the focus of various studies during the past years (Paas \& Vahi, 2012; Asheim, Smith, \& Oughton, 20II; Moreno \& Miguelez, 20II; Padilla, Vang, \& Chaminade, 2008). Meanwhile, more challenges in creating composite indicators that effectively measure regional innovative capacities, especially for countries with developing and transitional economies, need to be tackled. It is also noteworthy that the lack of available statistical data is a crucial problem for countries with developing and transitional economies (Bhutto et al., 2012; Tijssen \& Hollanders, 2006; Chen \& Dahlman, 2005;Archibugi \& Coco, 2004). Note also that obtaining of statistical information at the various levels of territorial classification is significantly different.

Our study focuses on the case of Georgia and reveals that, albeit the low level of accessibility of the statistical information, the composite indicators may be constructed and used to measure the current innovative development at the regional level for countries with developing and transitional economies. We have introduced the composite indicators GRIS and GCLS for measuring the regional innovative capacities (at GNUTSI and GNUTS2 levels, respectively) as well as included a brief analysis of the Georgian regions' innovative capacities for 2010 that has been determined by using the presented indicators. Georgia is a useful case-subject because its small-scale developing economy presents special challenges for employing composite indicators. Thus, the experience reported in this article probably will be of interest for other developing countries.
The article is organized as follows: Section 2 provides a discussion of the theoretical background for this study. Section 3 presents the methodology and procedure for analysis, including the steps used to generate the GRIS and GCLS indicators. Section 4 provides the results of the application of this indicator to the regions of Georgia. Finally, Section 5 provides some conclusions.

\section{Theoretical Background: Defining RIS}

Although the concept of RIS has been much debated in the scientific literature for the past 20 years, a conclusive consensus is yet to be formed. For example, Doloreux and Parto (2004) assert that "The concept of RIS has no commonly accepted definitions but usually is understood as a set of interacting private and public interests, formal institutions and other organizations that function according to organizational and institutional arrangements and relationships conducive to the generation, use and dissemination of knowledge" (p. 9).

In particular, the scientific literature on RIS requires to further scrutinize the accepted definitions of region and innovation. Several scholars have proposed different definitions for these concepts. For example, Cooke et al. (1997) explained region as "a territory less than its sovereign state, possessing distinctive supralocal administrative, cultural, political, or economic power and cohesiveness, differentiating it from its state and other regions" (p. 480).

The OECD/EUROSTAT Oslo Manual (2005) provides the following definition of innovation:"An innovation is the implementation of a new or significantly improved product (good or service), or process, a new marketing method, or a new organizational method in business practices, workplace organization or external relations" (p. 46). Meanwhile, Gregersen and Johnson (1997) defined the concept of innovation system as "The main idea of the concept of innovation systems is that the overall innovation performance of an economy depends not only on how specific organizations like firms and research institutes perform, but also on how they interact with each other and with the government sector in knowledge production and distribution. Innovating firms operate within a common institutional set-up and they jointly depend on contribute to and utilize a common knowledge infrastructure. It can be thought of as a system which creates and distributes knowledge, utilizes this knowledge by introducing it into the economy in the form of innovations, diffuses it and transforms it into something valuable, for example, international competitiveness and economic growth" (p. 5).

Based on these definitions, RIS can be said to be a social system that involves interaction among its constituent actors, 
for example, companies, research and academic organizations, regional administration, technical mediators, and other formal and informal institutions. We can also conclude that RIS necessarily exploits the accessible resources such as human, financial, infrastructural, and institutional resources at both the local and the national levels. Moreover, RIS requires the generation and dissemination of knowledge in addition to usage of innovations. Finally, we can conclude that the results of RIS help spur regional economic development. The above-mentioned points suggest that the RIS model should necessarily include the following components: resources, generation and utilization of knowledge, interaction among its constituent actors, and the results of innovation.

Importantly that the definitions mentioned above are in direct correspondence with the definition of clusters as perceived by Porter (Porter, 1998). According to Porter, a cluster is a geographical concentration of interrelated companies, specialized suppliers, service providers, and businesses operating in similar sectors as well as related institutions (governmental, educational etc.) in a particular field that collaborate and as well as compete. Consequently, a cluster consists of numerous diverse individuals from different areas of industry, education, science, and governmental institutions integrated in the unified structure. Obviously, this can, in totality, be considered as a reduced scale innovation system (OECD, 200I).

\section{Methodology and Procedure of Analysis}

\section{I. Defining the regions}

To practically study composite indicators at the regional level, it is important to first provide a working definition of the notion of a region. Practical definition of regions should consider the availability of statistical information for a given set of initial indicators. In our study, we considered the Georgian regions according to the GNUTS (Nomenclature of Territorial Units for Statistics in Georgia) system.

GNUTS divides Georgia in the GNUTSI regions, each of which is in turn subdivided into GNUTS2 regions. For technical reasons related to the difficulties of the enterprises location's classification in the Tbilisi (capital city of Georgia, which is a GNUTSI region and subdivided into few GNUTS2 regions), we considered Tbilisi also as a GNUTS2 region. This was possible because we used only the relative characteristics of the regions in our stady.After this decision, we obtained (by de facto status at 2010) II GNUTSI regions( Annex, Table I) and 64 GNUTS2 regions. Accordingly, we introduced two different composite indicators - GRIS for the GNUTSI level and GCLS for the GNUTS2 level.

\subsection{Defining the initial indicators}

Based on the theoretical discussions in Section 2 and along with the multilateral testing of the available data, we identified the following set of initial indicators for composite indicator GRIS (see the Annex A2 for detailed definition of these indicators):

Educational Level (EDL): This indicator reflects the professional skills of the regional labor force; it is represented by the share of working-age population with tertiary education. Infrastructure (INF): This indicator reflects the regional infrastructure development level; it is represented by the share of households equipped with personal computers.

Governmental Support (GSP): This indicator reflects the state support level; it is represented by the share of transfers from the state budget to the region under consideration.

Social Network (NET): This indicator reflects the existing social networks in the region; it identifies the citizens' levels of participation in various voluntary organizations.

Knowledge Generation (KNG): This indicator reflects the intellectual production in the region; it is represented by the patent applications.

Knowledge Intensive Production (KIP): This indicator characterizes employment in high and medium-high technology industries and knowledge intensive services.

Competitive Capacity (CMP): This indicator characterizes the value added per worker in the region.

Following comments concerning these indicators should be taken into consideration. In order to reflect the resource capability of RIS, we selected the indicators EDL, INF, and GSP. To measure the linkages or relationships among RIS's actors, we selected the indicator NET.To measure the generation and utilization of knowledge, we selected the indicators KNG and KIP. Finally, to capture the direct economic outcome of RIS, we selected the indicator CMP.

The indicators EDL, KNG and KIP (or their variations) are conventionally used in studies on innovation systems on national as well as regional levels (Hollanders, 2007; Ejermo, 2009). The indicators CMP and KIP (and their analogues) are widely used to measure the economic output through innovation. The indicator KNG is also often used as the indicator representing the "tacit output" of the innovation (Ajmone Marsan \& Maguire, 20I I). The indicator INF (or its analogues: Broadband access of firms, Internet users, etc.) are often used as the indicators of the (new) infrastructure development level (UNU-MERIT, 20I0; Castellacci \& Nat- 
era, 20I I). For countries where financial support of regions is contributed mostly from the central budget, such as for Georgia, GSP is probably the most appropriate indicator of the financial possibilities of the RIS. Here, GSP outlines the role of the government in its functioning. The linkages among actors is a vital component in the conception of RIS and are traditionally measured by indicators such as cooperation between actors and collaboration in various projects, which are difficult to acquire on the sub-national level ( $\mathrm{Aj}$ mone Marsan \& Maguire, 20II). Furthermore, due to the lack of other options, we also considered the NET indicator as an indirect measurement of the knowledge flow within RIS (Saisana, 2008). Also, NET was the sole indicator in this set that employed an external source of information, World Values Survey (WVS).

In addition, the above-mentioned initial indicators are impossible to obtain from the official statistical source at the GNUTS2 level. The data that can be obtained on the GNUTS2 level from the official statistical source are only employment data from the Business Register. Considering this, we used the following initial indicators (the exact definition of these indicators is provided in sub-section 3.4) for constructing the composite indicator GCLS: The employment size in a particular sector cluster within a region, the degree of specialization within a region, and the cluster focus of employment within a region. These indicators are usually used for analyzing clusters (European Commission, 2007). Considering that a cluster is a "reduced scale innovation system," we introduced the composite indicator GCLS, which is essentially a measure of the clusterization in the regions.

The composition of the composite indicators presented in this article may be subjected to criticism. Basically, any composite indicator should be considered as an evolving instrument, because its current design is based on the available knowledge on the object analyzed, the current practical requirements, and the availability of information. This is thus the consequence on the complex nature of RIS. In Section 4, we have reported that the minimal configuration of the composition of our composite indicators mentioned here enabled us to analyze the innovation capabilities of the Georgia regions.

\subsection{Construction of GRIS composite indicator}

This section describes the procedure used to construct the composite indicator GRIS. Assuming that represents a finite set of regions and $|R|=M$ represents its cardinality; $x_{i}: R \rightarrow^{\mathrm{o}}, 1 \leq i \leq N$ (where: ${ }^{\circ}$ is a set of real numbers, $N$ is number of initial indicators), and $x_{i}(r)(1 \leq i \leq N)$ is a value of indicator $i$ for the region $r$. We have assumed that all indicators have the same direction, that is, the lower value of the indicator corresponds to the "worse" value and the greater value corresponds to the "better" value. Because the initial indicators are represented in different scale units, it is reasonable to normalize them. We used a standardization procedure (z-scores) and obtained the normalized initial indicators:

$$
I(r)=\frac{1}{\sigma_{i}}\left(x_{i}(r)-\bar{x}_{i}\right), r \in R ;
$$

Where, $\bar{x}_{i}, \sigma_{i}$ are the mean and standard deviation of the indicator $i(1 \leq i \leq N)$, respectively.

The selection of a particular aggregation procedure is critical for the construction of composite indicators. To address this issue, we used the following simple and widely applied linear aggregation scheme:

$$
I(r)=\sum_{1 \leq i \leq N} w_{i} I_{i}(r), r \in R
$$

Where, $w_{i}\left(w_{i} \geq 0,1 \leq i \leq N ; \sum_{1 \leq i \leq N} w_{i}=1\right)$ is the weight of the normalized initial indicator.

The choice of weights is important and can occasionally contest the decision in such an analysis. We decided to use the factor analysis method for the choice of weights. This method allowed us to calculate the rotated loading factors of the normalized initial indicators. We decided to limit ourselves to four leading factors, whose interpretation corresponded with the conceptual scheme described in Section 2. These four factors gave $92 \%$ data variation.

We followed the approach of Nicoletti et al. (2000) to arrange the initial indicators within sub-indicators and to specify their weights. This procedure allowed us to arrange the normalized initial indicators within the following sub-indicators (Annex Table 2): Inner recourses - INRS (EDL, KGN, and INF); Connection with NIS - NISC (GSP, KIP); Social network - NETW (NET); and Competitive capacity CMPT (CMP). The values of the GRIS composite indicator and the corresponding sub-indicators for 2010 are presented in Annex Table 3.

To test the factor analysis results, we conducted a cluster analysis of the initial indicators (Fig I, panel A). The result obtained confirmed the correctness of grouping the initial indicators in the above-mentioned sub-indicators. 
A

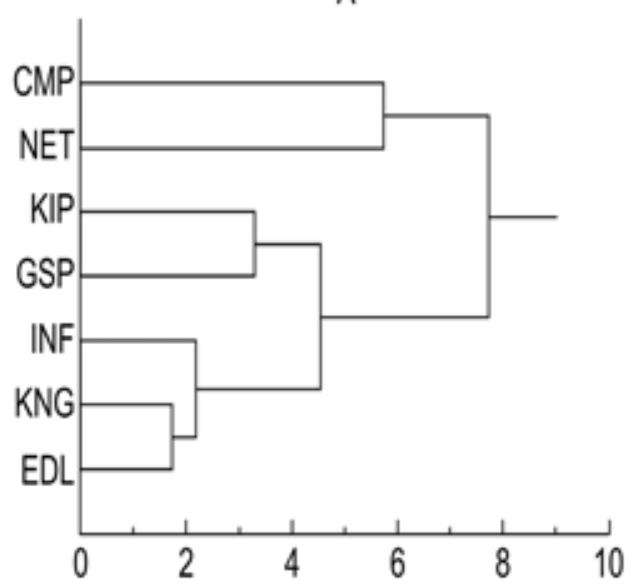

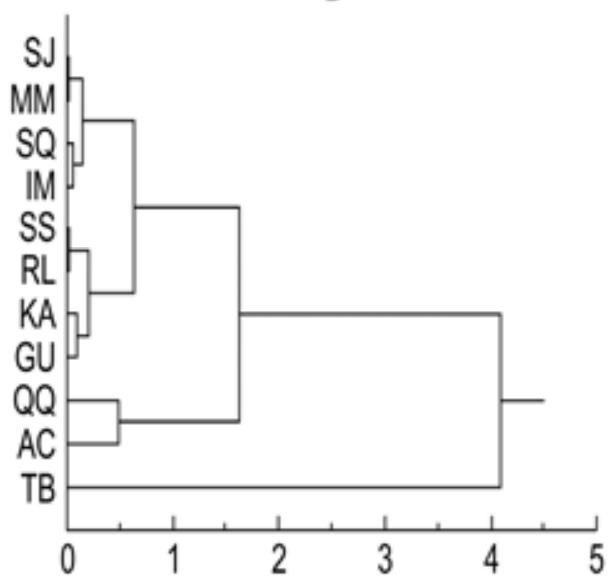

Fig I. Results of Cluster Analysis

Horizontal axis - Euclidean distance; Vertical axis - Objects: Panel A. GRIS-20I0 normalized initial indicators; Panel B- Georgia GNUTSI-regions (Annex Table I.)

\subsection{Construction of GCLS composite indicator}

This section describes the procedure used to construct the composite indicator GCLS. Assuming that $R, S$ represents a finite sets, with cardinality $|R|=M,|S|=N$, of regions and sectors, respectively, and defines a set of statistical clusters as $C=R \times S$. For any statistical cluster $c=(r(c), s(c)) \in C$ defined by $L_{c}$ the total employees in the cluster, $L_{r(c)}$ the total employees in the cluster's region, $r(c) \in R$, by $L_{s(c)}$ the total employees in the cluster's sector, $s(c) \in S$, and by $L$ the total employees in the country. For any cluster, $c=(r(c), s(c)) \in C$ define the following indicators: Size - $S Z(c)=L_{c} / L_{s(c)}$, Specialization - $S P(c)=\left(L_{c} / L_{r(c)}\right) /\left(L_{s(c)} / L\right)$, and Focus $F C(c)=L_{c} / L_{r(c)}$.

For normalization initial indicators, we used the following procedure. If $J: C \rightarrow \mathbb{R}$ represent some initial indicator (in our case-Employment size, Degree of specialization, and Cluster focus within a region), we defined normalized indicator, $\tilde{J}: C \rightarrow \mathbb{R}$, corresponding to initial indicator $J$, by equality: $J_{\text {norm }}(c)=\frac{1}{M N}\left|N_{J}(c)\right|$, where

$$
N_{J}(c)=\left\{c^{\prime} \in C \mid J\left(c^{\prime}\right)<J(c)\right\} \text { and }\left|N_{J}(c)\right| \text { its cardi- }
$$
nality. It should be noted that the normalization procedures similar to the one described above are often used in practice (Chen \& Dahlman, 2005).

Describe the clasterization level of a statistical cluster as an average:

$$
I(c)=\frac{1}{3}(\widetilde{S Z}(c)+\widetilde{S P}(c)+\widetilde{F C}(c)), c \in C
$$

and, considering that a set of statistical clusters, $C$, is "twodimensional," we can define the composite indicator GCLS as:

$$
I_{R}(r)=\frac{1}{3} \sum_{s \in S}(\widetilde{S Z}((r, s))+\widetilde{S P}((r, s))+\widetilde{F C}((r, s)))
$$

For constructing the GCLS-2010 composite indicator, we used a total of 64 regions at the GNUTS2 level and a total of 219 NACE3 sectors (Erostat, 2008) for Georgia at 2010. Note that only 2621 statistical clusters (I8.7\% from total) are "nonempty", i.e., $L_{c} \neq 0$ in our case. The values of the GCLS-2010 composite indicator and the ranking of the GNUTS2 regions are presented in Annex Table 4. Also, the averaging GCLS composite indicator at the GNUTSI level satisfactorily correlates with the GRIS indicator in the case of Georgia (Fig 2) and, consequently, it can be considered as an innovation capacity measure for the GNUTS2 regions. 


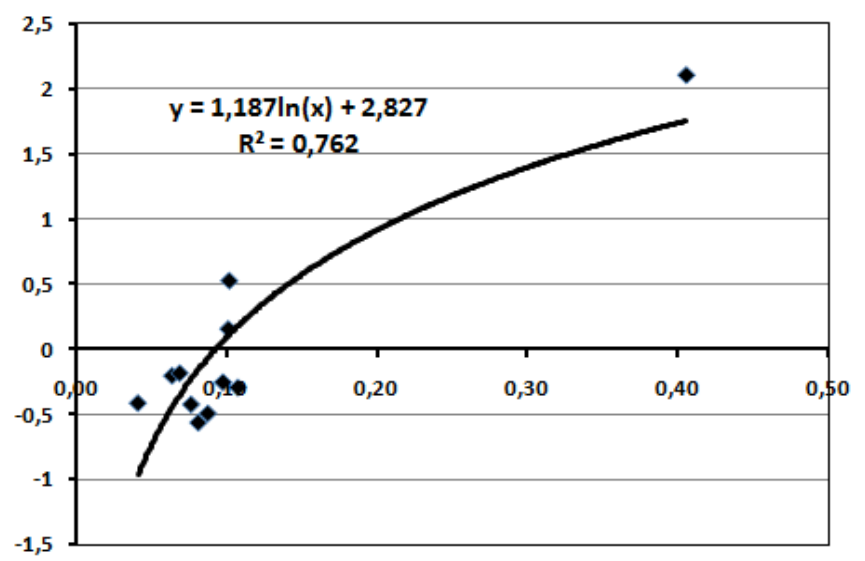

Fig 2. GCLS-20I0 vs. GRIS-20I0

Horizontal axis - GNUTSI-averaging of GCLS-20I0Vertical axis -GRIS-20I0
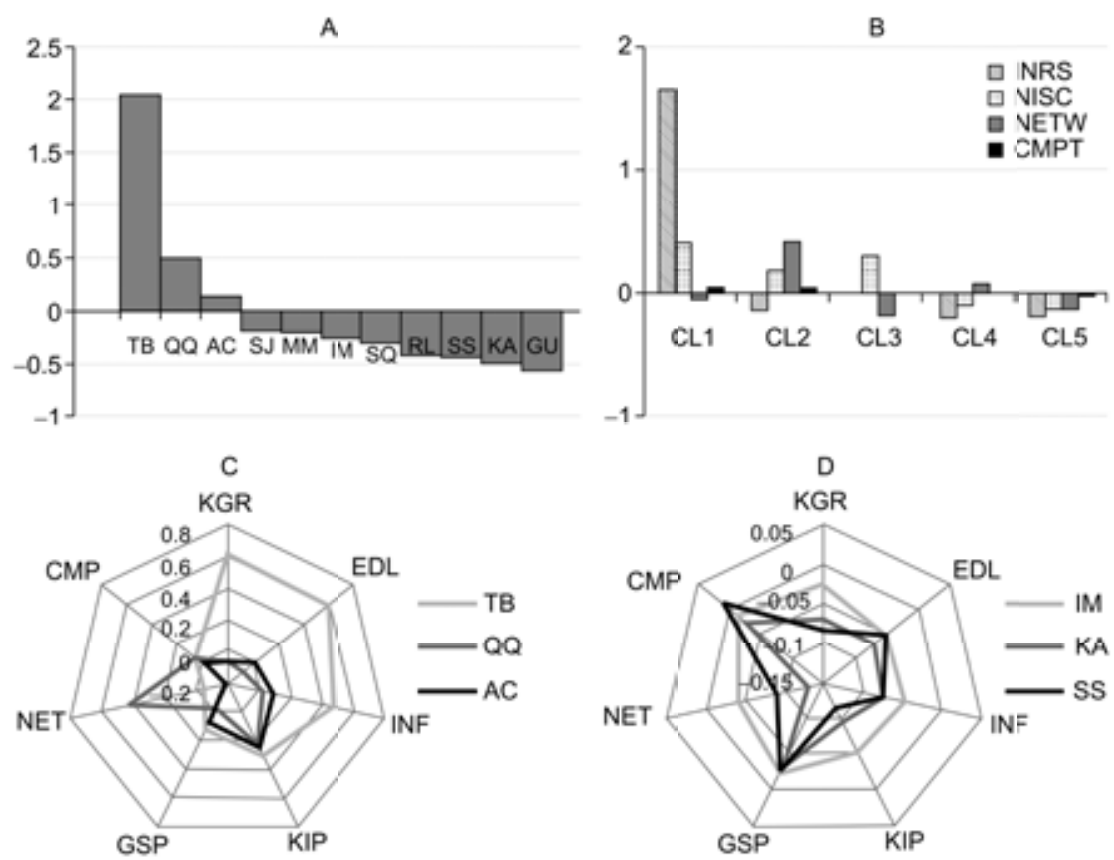

Fig 3. Heterogeneity of Georgia's RIS

\section{Results: A brief description of Georgia's RIS}

Using the GRIS-2010 and its sub-indicators, the analysis reveals that there is a considerable difference between the innovation system of the Georgia's regions (Fig 3, panels A and $B)$. Moreover, the inner resources of almost every region, except Tbilisi (TB) and Ajara (AC), were below the national average. Also, the connection with NIS of almost every region was also below the national average. A detailed analysis revealed that the differences between the regions' RIS are deeply rooted in the inequalities in factors such as education, infrastructure, governmental support, and generation knowledge capacities (Fig 3, panels C and D).
Panel A. Vertical axis - GRIS-2010 indicator's score, Horizontal axis - Georgia regions (Annex Table I); Panel B. Vertical axis - GRIS-20I0 sub-indicator's average score by GNUTSI-regional groups, Horizontal axis - GNUTSI-regional groups; Panels C, D - see Annex AI for regions' abbreviation and Annex A2 for GRIS-2010 normalized initial indicators' abbreviation.

Based on the cluster analysis conducted using GRIS-20I0 indicator, we obtained five group of GNUTSI regions (Fig I, panel A and Fig 4): CLI = (TB), CL2 = (QQ), CL3 $=(A C), C L 4=(I M, S Q, M M, S J)$, and CL5 = (GU, SS, RL, $K A)$, which further stresses the regional innovative dispari- 


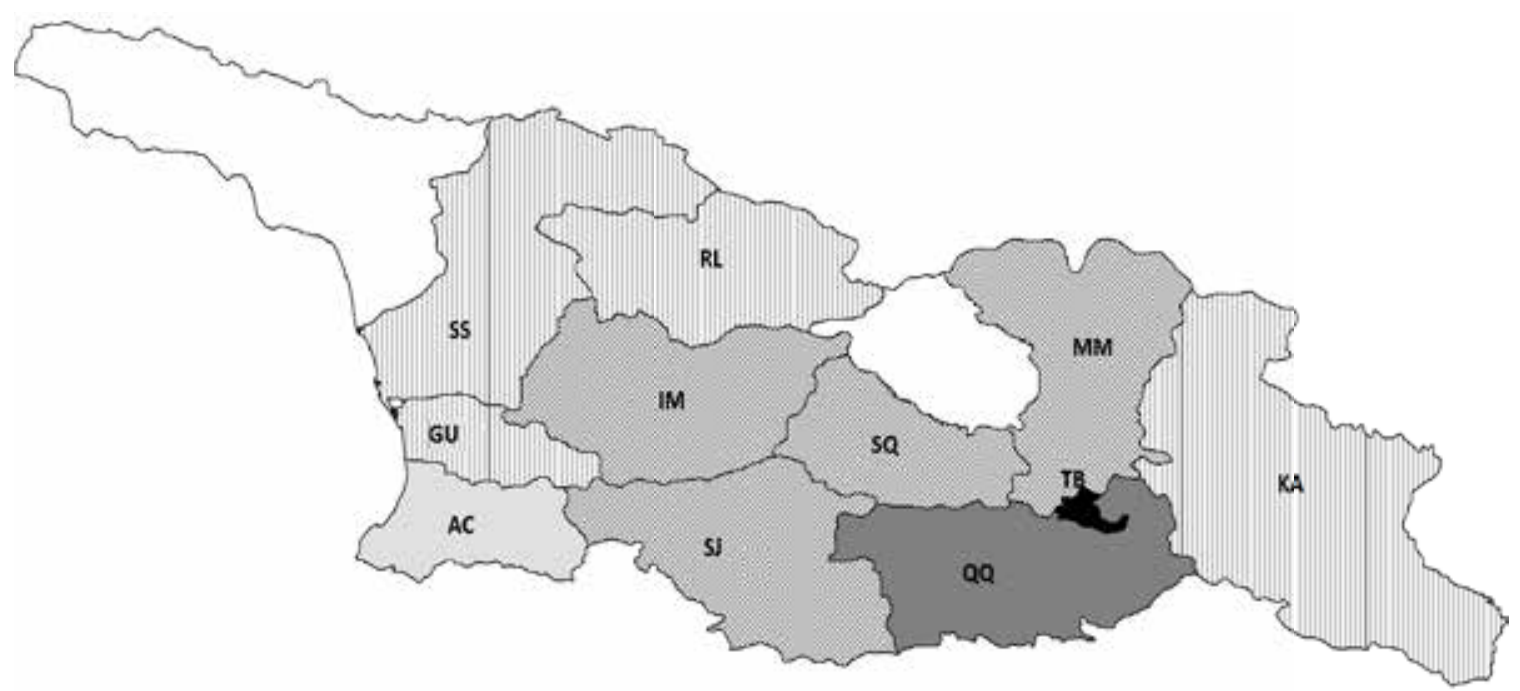

Fig 4. Georgia's GNUTSI-RIS grouping

ties in Georgia. Using the GCLS-2010 indicator, the analysis (Annex Table 4) reveals more impressive regional innovative disparities on the GNUTS2 level. Eliminating these regional inequalities is one of the most serious challenges that Georgia faces today.

\section{Conclusion}

RIS is the component of the national innovation system, and it determines the innovative potential of a country. Therefore, it is important to develop quantitative instruments to measure and monitor the working of RISs. RIS composite indicators could serve this purpose; however, until date, no effective tool has been developed for measuring the effects of RIS in developing countries. The present study addressed this gap in the literature by introducing a composite indicator to examine the case of RIS in Georgia.

The composite indicators GRIS and GCLS proposed in this study were developed using an available set of initial indicators. The application of this composite indicator revealed that this indicator has the capacity for effective regional analysis and can prove beneficial for policy makers that develop regional innovative policies. In particular, testing by using GRIS and GCLS indicators indicates the significant heterogeneity among the innovative capacities of the Georgian regions. However, our study is only the first step and much additional research is necessary for developing RIS composite indicators for countries with developing and transitional economies.

\section{Appendix}

\section{A.I.Table I (next page) \\ A.2. Initial Indicators for GRIS}

EDL - Educational Level:

This indicator is defined as the share of the population between the ages of 25 and 64 who have had tertiary education in the region.

Dimension: percent

Information source: Households general survey (Geostat)

INF - Infrastructure:

This indicator is defined as the share of households in the region that are equipped with a PC.

Dimension: percent

Information source: Households general survey (Geostat)

GSP -Governmental Support

This indicator is defined as the per capita transfers from the state budget to the region.

Dimension: GEL per capita

Information source: State budget (Ministry of Finance of Georgia) and Demographic statistics (Geostat)

NET - Social Nets

This indicator is defined as the share of regional residents who have stated that they are active members of at least one of the following voluntary organizations: sports and fitness, religious, arts and education, labor union, political parties, environmental, charity-humanitarian, or other. This information is captured through the questions V24-V33 of the World Values Survey.

Dimension: percent 


\begin{tabular}{|c|c|c|}
\hline N-Code & A-Code & REGION \\
\hline Tा & TB & Tbilisi (capital) \\
\hline T5 & $\overline{A C}$ & Ajara \\
\hline 23 & GU & Guria \\
\hline 26 & TM & Imereti \\
\hline 29 & $\mathrm{KA}$ & Rakheti \\
\hline 32 & MM & Mtskheta-Mtianeti \\
\hline 35 & RL & Racha-Lechkhumi-Qvemo Svaneti \\
\hline 38 & SS & Samegrelo-Zemo Svaneti \\
\hline 41 & SJ & Samtskhe-Javaxeti \\
\hline 44 & QQ & Qvemo Qartli \\
\hline 47 & SQ & Shida Qartli \\
\hline
\end{tabular}

A.I. Regions

Table I. Georgian Regions (GNUTSI)

\begin{tabular}{|c|c|c|c|c|}
\hline \hline \multirow{2}{*}{ Sub Indicator } & $\begin{array}{c}\text { Normalized } \\
\text { Initial Indicator }\end{array}$ & $\begin{array}{c}\text { Normalized Initial Indicator's } \\
\text { Weights in Sub Indicator }\end{array}$ & $\begin{array}{c}\text { Sub Indicator's } \\
\text { Weights }\end{array}$ & $\begin{array}{c}\text { Normalized Initial } \\
\text { Indicator's Weights }\end{array}$ \\
\hline \hline \multirow{3}{*}{ INRS } & KNG & 0.37 & \multirow{2}{*}{0.57} & 0.21 \\
\cline { 2 - 3 } & EDL & 0.35 & & 0.20 \\
\cline { 2 - 3 } & INF & 0.28 & 0.16 \\
\cline { 2 - 3 } & KIP & 0.77 & 0.22 & 0.17 \\
\cline { 2 - 5 } & GSP & 0.23 & 0.19 & 0.05 \\
\hline \multirow{2}{*}{ NISC } & NET & 1.00 & 0.03 & 0.19 \\
\hline CMPT & CMP & 1.00 & 0.03 \\
\hline
\end{tabular}

Table 2.Weights of normalized initial indicators and sub indicators for GRIS-20I0

Information source:World Values Survey

KNG - Knowledge Generation

This indicator is defined as a number of patent applications per 1000 labor force representatives. In the case of co-authors for an application, the index is divided proportionally for each co-author's region.

Dimension: Number of patents per 1000 labor force representatives

Information source: Patent applications (SAKPATENTI) and Labor statistics (Geostat)

KIP - Knowledge-intensive Production and Services

This indicator is defined as the share of people in the region employed in high and medium - high technology industries and knowledge-intensive services. High and medium - high technology industries and knowledge-intensive services are determined by standard classification (ISIC Rev.3).

Dimension: percent

Information source: Business register (Geostat).

CMP - Competitive Capacity

This indicator reflects value added per worker in the region. Dimension: 1000 GEL per employee.

Information source: Business statistics (Geostat).

Initial statistical data is available by special request or directly from the following sites:

Geostat - http://www.geostat.ge

Ministry of Finance of Georgia - http://www.mof.ge National Intelectual Property Center SAKPATENTI - http:// www.sakpatenti.org.ge

World Values Survey - http://www.worldvaluessurvey.org 


\begin{tabular}{|c|c|c|c|c|c|c|}
\hline GNUTS1-REGION & & INRS & NISC & NETW & CMPT & GRIS-2010 \\
\hline$\overline{\mathrm{TB}}$ & Tbilisi & 1.68 & 0.42 & -0.05 & 0.05 & 2.11 \\
\hline $\mathrm{AC}$ & Ajara & 0.02 & 0.32 & -0.18 & 0.00 & 0.16 \\
\hline GU & Guria & -0.15 & -0.13 & -0.25 & -0.02 & -0.56 \\
\hline $\mathrm{IM}$ & Imereti & -0.13 & -0.07 & -0.04 & -0.01 & -0.25 \\
\hline KA & Kakheti & -0.21 & -0.12 & -0.13 & -0.02 & -0.49 \\
\hline $\mathrm{MM}$ & Mtskheta-Mtianeti & -0.19 & -0.14 & 0.15 & -0.01 & -0.20 \\
\hline RL & Racha-Lechkhumi-Qvemo Svaneti & -0.21 & -0.13 & -0.04 & -0.04 & -0.41 \\
\hline SS & Samegrelo-Zemo Svaneti & -0.21 & -0.14 & -0.09 & 0.01 & -0.42 \\
\hline SJ & Samtskhe-Javaxeti & -0.31 & -0.05 & 0.17 & 0.01 & -0.18 \\
\hline QQ & Qvemo Qartli & -0.14 & 0.19 & 0.43 & 0.05 & 0.53 \\
\hline SQ & Shida Qartli & -0.16 & -0.15 & 0.03 & -0.01 & -0.29 \\
\hline
\end{tabular}

A.3. Composite Indicators GRIS-2010 and GCLS-2010 


\begin{tabular}{|c|c|c|c|c|c|c|c|}
\hline GNUTS2-Region & Code & GCLS & Rank & GNUTS2-Region & Code & GCLS & Rank \\
\hline Tbilisi C & 1100 & 0.405 & 1 & Akhmeta D & 2924 & 0.073 & 33 \\
\hline Batumi C & 1511 & 0.234 & 2 & Bagdadi D & 2623 & 0.071 & 34 \\
\hline Kutaisi C & 2611 & 0.224 & 3 & Lagodekhi D & 2932 & 0.071 & 35 \\
\hline Rustavi C & 4411 & 0.212 & 4 & Abasha D & 3823 & 0.071 & 36 \\
\hline Gori D & 4724 & 0.172 & 5 & Terjola D & 2631 & 0.068 & 37 \\
\hline Telavi D & 2930 & 0.145 & 6 & Tsalenjikha D & 3836 & 0.066 & 38 \\
\hline Zugdidi D & 3825 & 0.144 & 7 & Kharagauli D & 2637 & 0.065 & 39 \\
\hline Zestaphoni D & 2629 & 0.140 & 8 & Khobi D & 3838 & 0.064 & 40 \\
\hline Akhalcikhe D & 4129 & 0.129 & 9 & Dmanisi D & 4428 & 0.061 & 41 \\
\hline Marneuli D & 4432 & 0.123 & 10 & Khulo D & 1535 & 0.058 & 42 \\
\hline Khelvachauri D & 1532 & 0.123 & 11 & Chkhorotsku D & 3834 & 0.058 & 43 \\
\hline Photy C & 3814 & 0.120 & 12 & Kvareli D & 2938 & 0.058 & 44 \\
\hline Mtsketa D & 3229 & 0.115 & 13 & Tetritskaro D & 4430 & 0.056 & 45 \\
\hline Tskaltubo D & 2616 & 0.115 & 14 & Kareli D & 4728 & 0.054 & 46 \\
\hline Borjomi D & 4131 & 0.111 & 15 & Cokhatauri & 2327 & 0.054 & 47 \\
\hline Kobuleti D & 1525 & 0.108 & 16 & Martvili D & 3828 & 0.054 & 48 \\
\hline khashuri D & 4731 & 0.106 & 17 & Vani D & 2627 & 0.054 & 49 \\
\hline Bolnisi D & 4424 & 0.106 & 18 & Aspindza D & 4125 & 0.049 & 50 \\
\hline Samtredia D & 2633 & 0.106 & 19 & DuSeti D & 3225 & 0.049 & 51 \\
\hline Ozurgeti D & 2325 & 0.106 & 20 & Kazbeki D & 3231 & 0.049 & 52 \\
\hline Gardabani D & 4426 & 0.105 & 21 & Tsalka D & 4434 & 0.047 & 53 \\
\hline Sagarego D & 2934 & 0.105 & 22 & Ambrolauri D & 3523 & 0.045 & 54 \\
\hline Kaspi D & 4726 & 0.096 & 23 & Oni D & 3529 & 0.045 & 55 \\
\hline Gurjaani D & 2926 & 0.090 & 24 & Keda D & 1523 & 0.045 & 56 \\
\hline Senaki D & 3832 & 0.090 & 25 & Ninotsminda D & 4133 & 0.044 & 57 \\
\hline Sachkhere D & 2635 & 0.086 & 26 & Akhalqalaqi D & 4127 & 0.042 & 58 \\
\hline Ciatura D & 2618 & 0.084 & 27 & Tsageri D & 3531 & 0.042 & 59 \\
\hline Lanchkhuti D & 2323 & 0.083 & 28 & Tianeti D & 3227 & 0.041 & 60 \\
\hline Dedoplistskaro D & 2928 & 0.083 & 29 & Shuakhevi D & 1529 & 0.037 & 61 \\
\hline Khoni D & 2639 & 0.079 & 30 & Adigeni D & 4123 & 0.036 & 62 \\
\hline Tkibuli D & 2614 & 0.076 & 31 & Lenteki D & 3526 & 0.032 & 63 \\
\hline Signagi D & 2936 & 0.074 & 32 & Mestia D & 3830 & 0.019 & 64 \\
\hline
\end{tabular}

Table 4.Values of GCIS-20I0 Composite Indicator 


\section{References}

AJMONE Marsan, G., Maguire, K. (20II). Categorisation of OECD Regions Using Innovation-Related Variables. OECD Regional Development Working Papers, 201 I/03.

ARCHIBUGI, D., Coco,A. (2004). “New Indicator of Technological Capabilities for Developed and Developing Countries (ArCo)." World Development 32(4): 629-654.

ASHEIM, B., Smith, H., Oughton, C. (20II). Regional Innovation Systems: Theory, Empirics and Policy. Regional Studies, 45:7, pp. 875-891.

BHUTTO, A., Rashdi, P.L., Abro, Q.M. (2012). “Indicators for Science and Technology Policy in Pakistan: Entering the Science, Technology and Innovation Paradigm." Science and Public Policy 39: I- 12.

CASTELLACCI, F., Natera, J. (20II). A new panel dataset for cross-country analyses of national systems, growth and development (CANA). Norwegian Institute of International Affairs.

CHEN, D. H. C., Dahlman, C.J. (2005).The Knowledge Economy, the KAM Methodology and World Bank Operations. Washington, D.C.:The World Bank.

COOKE, P., Uranga M. J., Etxebarria, G. (1997). "Regional Innovation Systems: Institutional and Organizational Dimensions." Research Policy 26: 475-49I.

DOLOREUX, D., Parto, S. (2004). "Regional Innovation Systems: A Critical Synthesis." Institute for New Technologies, United Nations University.

EJERMO, O. (2009). "Regional Innovation Measured by Patent Data-Does Quality Matter?", Industry \& Innovation, Taylor and Francis Journals, vol. 16(2), pp. I4I-165,

EUROPEAN COMMISSION (2007). "Innovation Clusters in Europe: A statistical analysis and overview of current policy support", DG ENTERPRISE AND INDUSTRY REPORT, Europe Innova / PRO INNO Europe paper $n^{\circ} 5$

EUROSTAT (2008). "NACE Rev.2 Statistical classification of economic activities in the European Community", EUROSTAT

PAAS, T., Vahi, T. (20I2). "Regional Disparities And Innovations In Europe", European Regional Science Association, ERSA conference papers, ERSA I2, p80.
GREGERSEN, B., Johnson, B. (1997) “Learning Economies, Innovation Systems and European Integration." Regional Studies 3 I (5): 479-490.

HOLLANDERS, H. (2007). 2006 European Regional Innovation Scoreboard (2006RIS). Maastricht: MERIT.

KLENOW, P., Rodriguez-Clare, A. (1997). The Neoclassical Revival in Growth Economics: Has It Gone Too Far? , NBER Macroeconomics Annual 1997, 12, 73-103.

MORENO, R., Miguelez, E. (20I I)."A relational approach to the geography of innovation: a typology of regions", IREA Working Papers 201 121, University of Barcelona.

NICOLETTI, G., Scarpetta, S., Boylaud, O. (2000). "Summary Indicators of Product Market Regulation with an Extension to Employment Protection Legislation". Economics department working papers 226, ECO/WKP (99) I8, OECD.

OECD (200I). "Innovative Clusters. Drivers of National Innovative Systems". OECD

OECD/EUROSTAT (2005). "The Measurement of Scientific and Technological Activities. Oslo Manual (3rd edition)" , OECD.

PADILLA, R., Vang, J., Chaminade, C. (2008). RIS and Developing Countries: Linking firm technological capabilities to regional systems of innovation. WP 2008/I3, CIRCLE, Lund University.

PORTER, M.E. (1998). "Clusters and the new economics of competition," Harvard Business Review. Nov/Dec 1998, Vol. 76, Iss. 6 ,

SAISANA, M. (2008). 2007 Composite Learning Index: Robustness Issues and Critical Assessment. European Commission Joint Research Centre.

TIJSSEN R., and Hollanders H. (2006). Using science and technology indicators to support knowledge based economies. United Nations University.

UNU-MERIT (20I0). European Innovation Scoreboard (EIS) 2009:Comparativ analysis of innovation performance . European Union. 